\title{
Profile of European adults interested in internet-based personalized nutrition: The Food4Me Study
}

Article

Accepted Version

Livingstone, K., Celis-Morales, C., Navas-Carretero, S., SanCristobal, R., O'Donovan, C., Forster, H., Woolhead, C., Marsaux, C., Macready, A., Fallaize, R., Kolossa, S., Tsirigoti, L., Lambrinou, C., Moschonis, G., Godlewska, M., Surwiłło, A., Drevon, C., Manios, Y., Traczyk, I., Gibney, E., Brennan, L., Walsh, M., Lovegrove, J., Martinez, J., Saris, W., Daniel, H., Gibney, M. and Mathers, J. (2016) Profile of European adults interested in internet-based personalized nutrition: The Food4Me Study. European Journal of Nutrition, 55 (2). pp. 759-769. ISSN 1436-6215 doi: https://doi.org/10.1007/s00394015-0897-y Available at https://centaur.reading.ac.uk/39976/

It is advisable to refer to the publisher's version if you intend to cite from the work. See Guidance on citing.

To link to this article DOI: http://dx.doi.org/10.1007/s00394-015-0897-y

Publisher: Springer

All outputs in CentAUR are protected by Intellectual Property Rights law, including copyright law. Copyright and IPR is retained by the creators or other copyright holders. Terms and conditions for use of this material are defined in 
the End User Agreement.

www.reading.ac.uk/centaur

\section{CentAUR}

Central Archive at the University of Reading

Reading's research outputs online 
1 Title

2 Profile of European adults interested in internet-based personalized nutrition: The

$3 \quad$ Food4Me Study

4

5 Author names

6 Katherine M. Livingstone, Carlos Celis-Morales, Santiago Navas-Carretero, Rodrigo San-

7 Cristobal, Clare B. O’Donovan, Hannah Forster, Clara Woolhead, Cyril F.M. Marsaux, Anna L.

8 Macready, Rosalind Fallaize, Silvia Kolossa, Lydia Tsirigoti, Christina P. Lambrinou, George

9 Moschonis, Magdalena Godlewska, Agnieszka Surwiłło, Christian A. Drevon, Yannis Manios, Iwona Traczyk, Eileen R. Gibney, Lorraine Brennan, Marianne C. Walsh, Julie A. Lovegrove, J. Alfredo Martinez, Wim H. Saris, Hannelore Daniel, Mike Gibney, John C. Mathers, on behalf of the Food4Me Study.

Author affiliations

Human Nutrition Research Centre, Institute of Cellular Medicine, Newcastle University,

Newcastle Upon Tyne, UK (KML, katherine.livingstone@newcastle.ac.uk; CCM,

carlos.celis@newcastle.ac.uk; JCM, John.Mathers@newcastle.ac.uk)

Center for Nutrition Research, University of Navarra, Pamplona, Spain; CIBER Fisiopatología

Obesidad y Nutrición (CIBERobn), Instituto de Salud Carlos III, Madrid, Spain (SNC, snavas@unav.es; RSC, rsan.1@alumni.unav.es; JAM, jalfmtz@unav.es)

UCD Institute of Food and Health, University College Dublin, Belfield, Dublin 4, Republic of Ireland (CBD, cbhodonovan@hotmail.com; HF, hannah.forster@ucdconnect.ie; CW, clara.woolhead@ucdconnect.ie; EG, eileen.gibney@ucd.ie; LB, lorraine.brennan@ucd.ie; MCW, marianne.walsh@ucd.ie; MG, mike.gibney@ucd.ie) 
Department of Human Biology, NUTRIM School for Nutrition, Toxicology and Metabolism, Maastricht University Medical Centre, Maastricht, the Netherlands (CFMM,

c.marsaux@maastrichtuniversity.nl; WHMS,w.saris@maastrichtuniversity.nl)

Hugh Sinclair Unit of Human Nutrition and Institute for Cardiovascular and Metabolic Research, University of Reading, Reading, UK (ALM, a.I.macready@reading.ac.uk; RF, R.Fallaize@pgr.reading.ac.uk; JAL, j.a.lovegrove@reading.ac.uk)

ZIEL Research Center of Nutrition and Food Sciences, Biochemistry Unit, Technische Universität München, Germany (SK, silvia.kolossa@tum.de; HD, hannelore.daniel@tum.de) Department of Nutrition and Dietetics, Harokopio University, Athens, Greece (LT, tsirigoti.lydia@gmail.com; CPL, cplambrinos@gmail.com; GM, gmoschi@hua.gr; YM, manios@hua.gr)

National Food \& Nutrition Institute (IZZ), Poland (MG, mgodlewska@izz.waw.pl; AS, asurwillo@izz.waw.pl; IT, itraczyk@izz.waw.pl)

Department of Nutrition, Institute of Basic Medical Sciences, Faculty of Medicine, University of Oslo, Oslo, Norway (CAD, c.a.drevon@medisin.uio.no)

Pubmed indexing: Livingstone; Celis-Morales; Navas-Carretero; San-Cristobal; O’Donovan; Foster; Woolhead; Marsaux; Macready; Fallaize; Kolossa; Tsirigoti; Lambrinou; Moschonis; Godlewska; Surwiłło; Drevon; Manios; Traczyk; Gibney; Brennan; Walsh; Lovegrove, Martinez; Saris; Daniel; Gibney; Mathers

\section{Corresponding author; request for reprints}

Professor John C. Mathers

Human Nutrition Research Centre 
49 Institute of Cellular Medicine

50 Newcastle University

51 Biomedical Research Building

52 Campus for Ageing and Vitality

53 Newcastle upon Tyne

$54 \quad$ NE4 5PL

55 john.mathers@newcastle.ac.uk

56 Tel: +44 (0) 1912481133 Fax: +44 (0) 1912481101

57 Running title: Individuals interested in personalized nutrition

58

59 


\section{Abstract (words count $=\mathbf{2 5 0}$ )}

\section{Purpose}

Personalised intervention may have greater potential for reducing the global burden of noncommunicable diseases and for promoting better health and wellbeing across the life-span than the conventional "one size fits all" approach. However, the characteristics of individuals interested in personalised nutrition (PN) are unclear. Therefore, the aim of this study was to describe the characteristics of European adults interested in taking part in an internet-based PN study.

\section{Methods}

Individuals from seven European countries (UK, Ireland, Germany, the Netherlands, Spain, Greece and Poland) were invited to participate in the study via the Food4Me website (http://www.food4me.org). Two screening questionnaires were used to collect data on socio-demographic, anthropometric and health characteristics as well as dietary intakes.

\section{Results}

A total of 5662 individuals expressed an interest in the study (mean age $40 \pm 12.7$; range 1587 years). Of these $64.6 \%$ were female and $96.9 \%$ were Caucasian. Overall, $12.9 \%$ were smokers and $46.8 \%$ reported the presence of a clinically diagnosed disease. Furthermore, $46.9 \%$ were overweight or obese and $34.9 \%$ were sedentary during leisure time. Assessment of dietary intakes showed that $54.3 \%$ of individuals reported consuming at least 5 portions 
22 of fruit and vegetables per day, $45.9 \%$ consumed more than 3 servings of wholegrains and

$23 \quad 37.2 \%$ limited their salt intake to less than $5.75 \mathrm{~g}$ per day.

24

25 Conclusions

26 Our data indicate that individuals volunteering to participate in an internet-based PN study

27 are broadly representative of the European adult population, most of whom had adequate

28 nutrient intakes but who could benefit from improved dietary choices and greater physical

29 activity. Future use of internet-based PN approaches is thus relevant to a wide target

30 audience.

31

32 Trial registration - Clinicaltrials.gov NCT01530139

33 (http://clinicaltrials.gov/show/NCT01530139)

34 Key Words - Personalised nutrition, European profile, tailored intervention, internet-based,

35 randomized controlled trial. 


\section{Introduction}

Non-communicable diseases (NCD), are the leading cause of death and are responsible for 36 million global deaths annually [1]. With modifiable risk factors estimated to account for over $80 \%$ of premature deaths from CVD and cerebrovascular disease [2], lifestyle-based interventions, including diet and physical activity, have been identified as an effective strategy for minimising the burden of NCD [3]. However, realising this potential will require the development, testing and implementation of much more effective behaviour change interventions than are used conventionally [4-6]. To achieve such changes, interventions will need to move from a conventional "one size fits all" approach to more predictive, personalised, preventive and participatory interventions [7]. The concept of personalised nutrition (PN) has been developed based on emerging understanding of the interactions between diet, phenotype and genes on health [8]. In contrast with conventional 'one-size fits all' approaches to dietary intervention, PN aims to provide advice on an individual (or group) basis that is tailored to specific needs based on knowledge of current diet and phenotypic and/or genotypic information. However, public acceptability will be a key prerequisite for the successful implementation of PN [9]. A survey of 6000 individuals across eight European countries found that $27 \%$ of individuals were willing to undertake genetic testing for the purpose of PN [10]. The internet offers substantial opportunities for costeffective implementation of PN intervention strategies with the potential for scalability and reach [6]. With an estimated $85 \%$ of the European population now using the internet[11], knowledge of the characteristics of individuals who would be interested in receiving PN advice via the internet would be valuable for planning future lifestyle-based interventions aiming to reduce health inequalities and to improve overall public health. 
59

60

61

62

63

64

65

66

67

68

69

70

The Food4Me Proof of Principle (PoP) Study is an internet-based randomized controlled trial conducted across seven European countries designed to compare the effects of different levels of PN on dietary behaviour and other health-related outcomes [12]. The present paper describes the characteristics of individuals interested in internet-based PN advice who were screened for inclusion in the Food4Me PoP Study.

\section{Materials and methods}

The present paper outlines responses to the screening questionnaires provided by individuals who indicated an interest in participating in the Food4Me PoP randomized controlled trial. The protocol for the Food4Me PoP Study has been published elsewhere [12].

\section{Participant recruitment}

Recruitment was conducted between July 2013 and February 2014 across seven European countries, via the internet, to emulate an internet-based PN service. Participants indicated their interest in joining the study by voluntarily registering their details on the Food4Me website (http://www.food4me.org/), which was set up for the purposes of the study (see Online Resource 1, Figure S1). The Food4Me PoP recruitment sites were as follows:

University College Dublin (Ireland); Maastricht University (the Netherlands); University of Navarra (Spain); Harokopio University (Greece); University of Reading (United Kingdom; UK); National Food and Nutrition Institute (Poland); Technische Universität München (Germany). 
80

Local and national advertising of the study via the internet, radio, posters, e-flyers, social media and word of mouth were used to aid recruitment (see Online Resource 1, Figure S2).

\section{Screening Questionnaires}

Once participants registered their details on the Food4Me website and consented to take part in the study, they were assigned a unique username and password and asked to complete two online screening questionnaires.

\section{First Screening Questionnaire}

The first screening questionnaire contained nine items on one screen. Individuals were asked to provide their age and sex, as well as information on internet access, pregnancy, food intolerances and allergies, since these data were used as exclusion criteria for the later randomized controlled trial $(\mathrm{RCT})$.

\section{Second Screening Questionnaire}

Participants eligible for inclusion in the RCT completed a second online questionnaire. The primary purpose of this questionnaire was to collect detailed socio-demographic, health, anthropometric and dietary data. Following completion of this questionnaire, participants were asked to complete a screening food frequency questionnaire (FFQ) to estimate habitual dietary intake. The online Food4Me FFQ included 157 food items consumed frequently in each of the seven recruitment countries and intakes of foods and nutrients were computed in real time using a food composition database. The FFQ and food composition database were developed and validated specifically for the Food4Me PoP study 
$103[13,14]$. In the present analysis, dietary intakes of foods and food groups were assessed

104

105 against six dietary recommendations: eat at least 5 portions of fruit and vegetables every day; eat at least 3 portions of wholegrain products every day; eat at least 1 portion of oily fish per week; eat less than 3 portions of red meat and processed meat per week; consume less than $5.75 \mathrm{~g} /$ day of salt and consume less than $10 \%$ energy from sugars.

Anthropometric measurements and physical activity

Body weight and height were self-measured and self-reported by participants via the internet. Occupational and non-occupational physical activity were self-reported via the internet prior to completion of the FFQ. Participants were asked to categorise their occupational physical activity as light (e.g. administrative and managerial), moderate (e.g. sales worker) or heavy (e.g. equipment operator) and their non-occupational physical activity as sedentary (little walking/cycling/exercise), moderately active (intense exercise lasting 20-45 minutes at least twice per week) or very active (intense exercise lasting at least an hour per day).

Ethical approval and participant consent

The Research Ethics Committees at each University or Research Centre delivering the intervention granted ethical approval for the study. The Food4Me trial was registered as a Randomized Clinical Trial (NCT01530139) at Clinicaltrials.gov. All participants who expressed an interest in the study were asked to sign online consent forms at two stages in the screening process: prior to submitting any details and prior to the screening FFQ. These consent forms were automatically directed to the local study investigators to be countersigned and archived. All Ethical Committees accepted an online informed consent 
127 procedure, except for The Netherlands and Germany whose ethics committees requested 128 an additional written informed consent form for participants who registered to participate 129 in the study. In the latter countries, hard copy consent forms were sent by post to the respective recruitment centres. Personal information from respondents was stored on a secure, password-protected server.

Data were analysed using Stata (version 13; StataCorp., College Station, TX, USA). Results from descriptive analyses are presented as means and SD for continuous variables or as percentages for categorical variables. Chi squared tests and multinomial regression analyses were used to test for significant differences across categorical variables. For multinomial comparisons across countries, the overall average was used as the reference group. ANOVA and Fisher-Hayter pairwise comparisons were used for continuous variables. Results were deemed significant at $\mathrm{P}<0.05$.

\section{Results}

Participant characteristics at first screening

144 A total of 5562 individuals registered their name and contact details on the Food4Me website (http://www.food4me.org/) and a total of 5442 individuals completed the first screening questionnaire (Tables 1 and 2). The completion rate for this questionnaire was 
questionnaire. Of the individuals who consented to participate in the study, $64.6 \%$ were female and $64.0 \%$ were below 45 years of age.

A total of 1631 individuals were ineligible for the subsequent RCT based on the first screening questionnaire. This was due mainly to having a food allergy or intolerance and/or not completing the second screening questionnaire (Figure 1). Reported food allergies and intolerances were more common among females than males (Table 1). Inter-country differences for the prevalence of therapeutic diets, food allergies and intolerances are presented in Table 2. The most common means of recruitment to the study was through magazines and newspaper articles, followed by word of mouth, but this varied by country and age group. Social media were responsible for recruiting more than three times as many individuals under, than over, the age of 45 years (Table 1 ).

\section{Participant characteristics at second screening}

Characteristics of the 3811 subjects who completed the second screening questionnaire are summarised in Tables 3 and 4. The completion rate for this questionnaire was $68.5 \%$ with 1751 individuals choosing to not proceed to the second screening questionnaire. The profile of these participants was similar to that of the whole cohort who expressed an initial interest in the Food4Me study: $62.4 \%$ were female and $62.8 \%$ were younger than 45 years of age. The percentage of females at this screening stage was more comparable across countries (range 56.6- 73.8\%) than at the initial screening (range 48.7-77.3\%). We observed that $96.9 \%$ of the participants were Caucasian. 
171 Obesity prevalence and reported health status

172 Nearly half (46.9\%) of participants were classified as overweight or obese but this

173 proportion varied considerably by sex, age and country (Table 3 and 4). As summarised in

174 Tables 5 and 6, nearly half (44.6\%) of individuals reported that they were on medication:

$17533.2 \%$ on prescribed and $11.5 \%$ non-prescribed medication. Prescribed and non-prescribed

176 medication use was higher in females than males ( $38 \%$ vs. $25 \%$ and $13.1 \%$ vs. $8.7 \%$

177 respectively) and higher in individuals over the age of 45 years ( $44.8 \%$ vs. $26.3 \%$ and $14.5 \%$

vs. 9.6\% respectively; see Online Resource 1 Table S1). Prescribed medication use was

179 higher in Germany (38.5\%) and The Netherlands (47.4\%) and lower in Spain (28.4\%),

compared with overall, whereas non-prescribed medication use was higher in Poland

181

(17.9\%) and Germany (16.3\%), compared with overall (see Online Resource 1 Table S2). In addition, $47.3 \%$ of individuals indicated that they were suffering from one or more clinically diagnosed diseases. Overall, $19.9 \%$ of individuals reported having an allergy, with the highest prevalence in Spain (26.9\%) and lowest in Ireland (13.3\%). Furthermore, 9.3\% of individuals reported high blood pressure which was more common in males than in females ( $12.6 \%$ vs. $7.3 \%)$, and among individuals over, than under, the age of 45 years ( $18.9 \%$ vs.

3.6\%; see Online Resource 1 Table S1). The prevalence of type I or type II diabetes was only $0.9 \%$, but was higher in individuals over, than under, the age of 45 years ( $1.8 \%$ vs. $0.4 \%$ ). On average, $12.9 \%$ of individuals were current smokers and smoking prevalence was more than five times higher in Greece than in the UK (see Online Resource 1 Table S1). 
193

Nearly three quarters of the individuals $(75.4 \%)$ indicated an interest in the Food4Me study because they were interested in PN, while $80.7 \%$ were interested in learning about what foods were best for them (Table 4). These results varied little by sex but slightly more individuals under, than over, the age of 45 years were interested in PN (Table 3). Just over half of individuals (50.6\%) indicated that their reason for registering with the study was due to a desire to lose $(48.8 \%)$ or, much less commonly, gain $(1.9 \%)$ weight. When asked if their interest was due to concerns for their health and well-being, up to $87.5 \%$ of the participants selected this option (Table 4). The proportion of individuals interested in health and wellbeing did not vary much by sex but was slightly higher in individuals over, than under, the age of 45 years (Table 3 ).

\section{Dietary intake and physical activity characteristics}

A total of 2764 individuals provided complete data on dietary intake and PA at screening. The completion rate for this questionnaire was $77.3 \%$, with 811 individuals choosing not to complete the screening FFQ after providing a second consent. Comparisons of screenees' dietary intakes with current dietary recommendations in Europe that were used in this study are presented in the Online Resource 1 Table S3, Figure S3-S6. Regarding fruit and vegetables intake $54.3 \%$ of individuals reported consuming at least five portions per day and the mean intake of the cohort $(651.4 \mathrm{~g}, \mathrm{SD} 488.6)$ was greater than the WHO/FAO recommended minimum of $400 \mathrm{~g}$ per day [15]. Just under half of participants (45.9\%) consumed at least three portions of wholegrains per day. A third of participants (36.3\%) consumed more than one portion of oily fish per week. Two thirds (66.2\%) of individuals consumed less than three portions $(450 \mathrm{~g})$ of red or processed meat weekly. Furthermore, 
only $37.2 \%$ of individuals consumed less than $5.75 \mathrm{~g}$ of salt per day (mean $7.56 \mathrm{~g}$, SD 4.88).

Overall, only $2.1 \%$ of participants consumed less than $10 \%$ energy from sugars. Nearly three quarters (72.9\%) of individuals reported being in light/sedentary occupations, whereas only 34.9\% of individuals were sedentary during leisure time (Table 3 and 4).

\section{Discussion}

Main findings

The present paper characterised the 5562 individuals who registered interest in participating in the Food4Me PoP PN intervention. Our main findings are that the European individuals interested in participating in an online PN study were not restricted to one specific group of individuals. Potential volunteers in the Food4Me PoP Study were broadly representative of the European adult population, most of whom had adequate nutrient intakes but could benefit from improved dietary choices and more physical activity to reduce their risk of common non-communicable diseases [16].

\section{Comparison with other studies}

The Food4Me PoP study is the first pan-European internet-based PN intervention study to collect detailed characteristics of individuals who would be interested in using such a service. However, a recent study across six European countries indicated that individuals over 65 years of age would be more interested in undertaking a genetic test for the purpose of PN than adults aged 25 to 34 years (55\% vs. 28.5\%) [10]. Our findings identified that interest in PN was a strong motivator for participating in the study, and that this was 
comparable across ages, sexes and countries. Stewart-Knox et al. [10] found that slightly more (2.2\%) females than males would be interested in having a genetic test done for the purposes of PN. Our findings confirm these results and suggest that females are more interested in participating in nutrition interventions [17], including those delivered via the internet [18]. Furthermore, we observed that females were more likely than men to be interested in participating in this study because of a desire to lose weight.

The percentage of overweight adults in different European countries ranges between $30 \%$ and $70 \%$ [19] and the prevalence of obesity in Europe is between $4 \%$ and $36.5 \%$, with higher prevalence in Central, Eastern, and Southern Europe than in Western and Northern Europe [20]. Recent estimates from the Organisation for Economic Co-operation and Development suggest that the average prevalence of obesity among EU adults is $16.6 \%$ [21], which is similar to the prevalence of obesity in individuals who registered to participate in the present study (15.7\%).

There is strong evidence in support of an inverse relationship between PA and CVD risk [22]. Despite this, according to the WHO, $69 \%$ of European adults fail to achieve at least half an hour of moderate-intensity PA on most days of the week [23]. Our data confirm these trends in the work place, with only $27.1 \%$ of individuals being moderately active at work, but suggest that during leisure time, $65.1 \%$ of individuals undertake intense exercise lasting at least 20-45 minutes at least twice per week.

Our results suggest that less than half of screenees adhered to most of the major European food-based dietary recommendations. This is consistent with the most recently available EU-wide data which show that mean intakes of fruit and vegetables in Germany (371g/day), Ireland (355g/day), the Netherlands (359g/day) and the UK (343g/day) [24] are less than the recommended $400 \mathrm{~g} /$ day (equivalent to 5 portions). Although we found that mean fruit and 
vegetable intake was greater than $400 \mathrm{~g}$, it should be noted that these estimates of fruit and vegetable intakes were obtained using a 157 item FFQ [14] and there is evidence that FFQs may over-estimate dietary intakes [25], especially when they include larger numbers of food items [26]. Importantly, the FFQ used in the present study was validated against a four-day weighed record [13,14]. Recent country-specific Nutrition, Physical Activity and Obesity reports by the WHO suggest that, with the exception of Greece (data unavailable), mean salt intake is in excess of $5.75 \mathrm{~g}$ per day across all six countries that provided participants for the present study[16]. These data are in line with our findings, where reported mean salt intakes ranged between $6 \mathrm{~g}$ in Greece and $8.3 \mathrm{~g}$ in The Netherlands. The current UK and WHO draft recommendations to limit sugars intake to less than $10 \%$ energy $[27,28]$ were met by very few of our participants and only one individual out of the 5562 screenees would meet the recent proposal to limit sugars intake to less than 5\% energy. In addition, the reported mean percentage energy from sugars in our study $(21.4 \%)$ is comparable with the recent estimate of $19.1 \%$ for the UK from the National Diet and Nutrition Survey [29]. Overall, our observations suggest that the dietary inadequacies of the individuals interested in PN in the present study are comparable with those of the wider European population.

Individuals with ill-heath, or with a food allergy or intolerance, may benefit from PN [10]. We found that $12.4 \%$ of the screenees declared a food allergy or intolerance. This prevalence is comparable with a recent finding that, among European adults, $11.5 \%$ selfreported the presence of a food allergy (cow's milk, egg, wheat, soy, peanut, tree nuts, fish and shell-fish) [30]. Furthermore, a large proportion of our participants reported being on medication (44.6\%) or suffering from a disease (47.3\%). These results are in line with data from Stewart-Knox et al. [10], which showed that interest in having a genetic test performed for the purposes of PN is higher in individuals with central obesity (38.4\%) and high blood 
287

pressure (38.1\%), than individuals with no signs of the metabolic syndrome (22.1\%). These findings confirm that those interested in PN include those for whom an effective dietary and/or physical activity intervention is likely to improve their health.

Strengths and limitations

The Food4Me PoP Study data were collected from a relatively large number of European adults, with a wide age range, who demonstrated their interest in PN by registering to join the Food4Me PoP Study. The two stage consenting process enabled the capture of data on individuals who were interested in a PN service but were not necessarily eligible to be included in the subsequent RCT. These characteristics included demographic information, adiposity, habitual physical activity, disease status, prevalence of food allergies and intolerances and dietary intake. A potential limitation of the study is that our data were obtained by self-report via the internet, which may have introduced measurement error. However, there is no reason to believe that such data are more likely to be mis-reported than data collected by conventional face-to-face interview or by paper-based questionnaires [31]. The validity of internet-based, self-reported anthropometric data is high [32] and this been confirmed in the present study (Celis-Morales $\mathrm{C}$ et al., paper submitted).

Implications for health professionals

Improving diet and lifestyle behaviours is a key element in national and international strategies for reducing the risk of NCDs and improving overall health across the life-span. However, realising this potential will require the development, testing and implementation of much more predictive, personalised, preventive and participatory interventions to achieve effective behavioural changes. Moreover, using the internet as a delivery method is 
311 likely to be an important route to scalable and sustainable interventions [6]. Characterising

312 those individuals who are interested in PN and its delivery via the internet will be valuable

313 information for the future design and implementation of PN interventions aiming to

314 improve health and to reduce health inequalities. The present results suggest that those

315 who registered to participate in this internet-based PN study were broadly representative of

316 the European adult population in terms of demographic, anthropometric and health

317 characteristics. Our findings provide strong evidence for the use of internet-based PN for

318 engaging individuals who would benefit from improved lifestyle behaviours and a reduction

319 in risk of obesity and NCDs. 


\section{Abbreviations}

Cardiovascular disease (CVD); Food frequency questionnaire (FFQ); Non-communicable diseases (NCD); Personalized nutrition (PN); Proof of Principle (PoP); Randomized controlled trial $(\mathrm{RCT})$

\section{Competing interests}

None of the authors had a personal or financial conflict of interest.

\section{Authors' contributions}

The authors' responsibilities were as follows: YM, IT, CAD, ERG, LB, JAL, JAM, WHMS, HD, MG and JCM contributed to the research design. JCM was the Proof of Principle study leader. CCM, CFMM, HF, CBO, CW, AM, RF, SNC, RSC, SK, LT, CPL, MG, AS, MCW, ERG, LB and JCM contributed to the developing the Standardised Operating Procedure for the study. CCM, SNC, RSC, CW, CBO, HF, CFMM, AM, RF, SK, LT, CPL, MG, AS, MCW and JCM conducted the intervention. CCM, CFMM and WHMS contributed to physical activity measurements. KML and CCM drafted the paper and performed the statistical analysis for the manuscript and are joint first authors. All authors contributed to a critical review of the manuscript during the writing process. All authors approved the final version to be published.

\section{Acknowledgments}

Study approval: The Foo4Me study has been reviewed and approved by seven independent ethical research committees in each of the countries involved in the trial. Patient consent: All participants, both screened and randomized, have given consent to take part in this study. Funding statement: This work was supported by the European Commission under the 
344 Food, Agriculture, Fisheries and Biotechnology Theme of the 7th Framework Programme for 345 Research and Technological Development [265494] 


\section{References}

1. Alwan A (2010) Global status report on noncommunicable diseases 2010.

2. Nichols M, Townsend N, Luengo-Fernandez R, Leal J, Gray A, Scarborough P, Rayner M

349 (2012) European Cardiovascular Disease Statistics.

350

3. Ketola E, Sipilä R, M. M (2000) Effectiveness of individual lifestyle interventions in reducing cardiovascular disease and risk factors. Ann Med 32 (4):239-251

4. Health and Social Care Information Centre NHS (2012) Health Survey for England - 2011, Trend tables. http://www.hscic.gov.uk/catalogue/PUB09302. Accessed 20 August 2014 FF, White M, Mathers JC (2014) Effectiveness of dietary interventions among adults of retirement age: a systematic review and meta-analysis of randomized controlled trials. BMC Med 8 (12):60

6. Celis-Morales C, Lara J, Mathers JC (2014) Personalising nutritional guidance for more effective behaviour change. Proc Nutr Soc 12:1-9. doi:doi:10.1017/S0029665114001633

7. Hood L, Friend SH (2011) Predictive, personalized, preventive, participatory (P4) cancer medicine. Nat Rev Clin Oncol 8 (3):184-187

8. Gibney MJ, Walsh MC (2013) The future direction of personalised nutrition: my diet, my phenotype, my genes. Proc Nutr Soc 72 (02):219-225. doi:doi:10.1017/S0029665112003436

9. Dar-Nimrod I, Cheung BY, Ruby MB, Heine SJ (2014) Can merely learning about obesity genes affect eating behavior? Appetite 81 (0):269-276.

doi:http://dx.doi.org/10.1016/j.appet.2014.06.109

10. Stewart-Knox BJ, Bunting BP, Gilpin S, Parr HJ, Pinhão S, Strain JJ, de Almeida MDV, 
representative sample of European consumers. Br J Nutr 101 (07):982-989.

doi:doi:10.1017/S0007114508055657

11. Eurostat (2010) Life Online.

12. Celis-Morales C, Livingstone K, Marsaux CM, Forster H, O'Donovan C, Woolhead C, Macready A, Fallaize R, Navas-Carretero S, San-Cristobal R, Kolossa S, Hartwig K, Tsirigoti L, Lambrinou C, Moschonis G, Godlewska M, Surwiłło A, Grimaldi K, Bouwman J, Daly EJ, Akujobi V, O’Riordan R, Hoonhout J, Claassen A, Hoeller U, Gundersen T, Kaland S, Matthews JS, Manios Y, Traczyk I, Drevon C, Gibney E, Brennan L, Walsh M, Lovegrove J, Alfredo Martinez J, Saris WM, Daniel H, Gibney M, Mathers J (2014) Design and baseline characteristics of the Food4Me study: a web-based randomised controlled trial of personalised nutrition in seven European countries. Genes Nutr 10 (1):1-13. doi:10.1007/s12263-014-0450-2

13. Fallaize R, Forster H, Macready LA, Walsh CM, Mathers CJ, Brennan L, Gibney RE, Gibney JM, Lovegrove AJ (2014) Online Dietary Intake Estimation: Reproducibility and Validity of the Food4Me Food Frequency Questionnaire Against a 4-Day Weighed Food Record. J Med Internet Res 16 (8):e190. doi:10.2196/jmir.3355

14. Forster H FR, Gallagher C, O'Donovan CB, Woolhead C, Walsh MC, Macready AL, Lovegrove JA, Mathers JC, Gibney MJ, Brennan L, Gibney ER (2014) Online Dietary Intake Estimation: The Food4Me Food Frequency Questionnaire. J Med Internet Res 16 (6):e150 15. World Health Organization (2003) Diet, nutrition and the prevention of chronic diseases. Report of a Joint FAO/WHO Expert Consultation. (WHO Technical Report Series, No. 916). 16. World Health Organization (2013) Country profiles on nutrition, physical activity and obesity. 
17. French SA, Jeffery RW, Wing RR (1994) Sex differences among participants in a weightcontrol program. Addict Behav 19 (2):147-158. doi:http://dx.doi.org/10.1016/0306$\underline{4603(94) 90039-6}$

18. Kodama S, Saito K, Tanaka S, Horikawa C, Fujiwara K, Hirasawa R, Yachi Y, lida KT, Shimano H, Ohashi Y, Yamada N, Sone H (2012) Effect of web-based lifestyle modification on weight control: a meta-analysis. Int J Obesity 36 (5):675-685

19. World Health Organization (2014) The challenge of obesity - quick statistics.

http://www.euro.who.int/en/health-topics/noncommunicable-diseases/obesity/data-andstatistics. Accessed 28 June 2014

20. Berghofer A, Pischon T, Reinhold T, Apovian C, Sharma A, Willich S (2008) Obesity prevalence from a European perspective: a systematic review. BMC Public Health 8 (1):200 21. OECD (2012) Health at a Glance: Europe 2012.

22. Mora S, Cook N, Buring JE, Ridker PM, Lee IM (2007) Physical Activity and Reduced Risk of Cardiovascular Events: Potential Mediating Mechanisms. Circulation 116 (19):2110-2118. doi:10.1161/circulationaha.107.729939

23. Physical activity and health in Europe: evidence for action (2006)

http://www.euro.who.int/en/health-topics/disease-prevention/physical-

activity/publications/2006/physical-activity-and-health-in-europe-evidence-for-action.

Accessed 28 June 2014

24. European Fresh Produce Association (2012) A Review of the EU regime for the fruit and vegetables sector.

25. Krebs-Smith SM, Heimendinger J, Subar AF, Patterson BH, E. P (1995) Using food frequency questionnaires to estimate fruit and vegetable intake: association between the number of questions and total intake. Journal of Nutrition Education 27:80-85 
416

417

418

419

420

421

422

423

424

425

426

427

428

429

430

431

432

433

434

435

436

437

438

26. Cade JE, Burley VJ, Warm DL, Thompson RL, Margetts BM (2004) Food-frequency questionnaires: a review of their design, validation and utilisation. Nutr Res Rev 17 (01):522. doi:doi:10.1079/NRR200370

27. SACN (2014) Draft Carbohydrates and Health Report.

28. World Health Organisation (2014) WHO opens public consultation on draft sugars guideline. http://www.who.int/mediacentre/news/notes/2014/consultation-sugarguideline/en/. Accessed 1 October 2014

29. Bates B, Lennox A, Prentice A, Bates C, Page P, Nicholson SK, Swan G (2014) National Diet and Nutrition Survey Results from Years 1, 2, 3 and 4 (combined) of the Rolling Programme (2008/2009-2011/2012).

30. Nwaru BI, Hickstein L, Panesar SS, Roberts G, Muraro A, Sheikh A, the EFA, Anaphylaxis Guidelines G (2014) Prevalence of common food allergies in Europe: a systematic review and meta-analysis. Allergy:12423. doi:10.1111/all.12423

31. Cook C (2010) Mode of administration bias. J Man Manip Ther 18 (2):61-63. doi:doi:10.1179/106698110X12640740712617

32. Pursey K, Burrows LT, Stanwell P, Collins EC (2014) How Accurate is Web-Based SelfReported Height, Weight, and Body Mass Index in Young Adults? J Med Internet Res 16 (1):e4. doi:10.2196/jmir.2909

33. Institute of Medicine (2010) Strategies to reduce sodium intake in the United States. 34. Goldberg GR, Black AE, Jebb SA, Cole TJ, Murgatroyd PR, Coward WA, Prentice AM (1991) Critical evaluation of energy intake data using fundamental principles of energy physiology: 1. Derivation of cut-off limits to identify under-recording. Eur J Clin Nutr 45:569581 
Table 1 Characteristics of individuals by sex and age; data obtained from the first screening questionnaire ${ }^{1}$

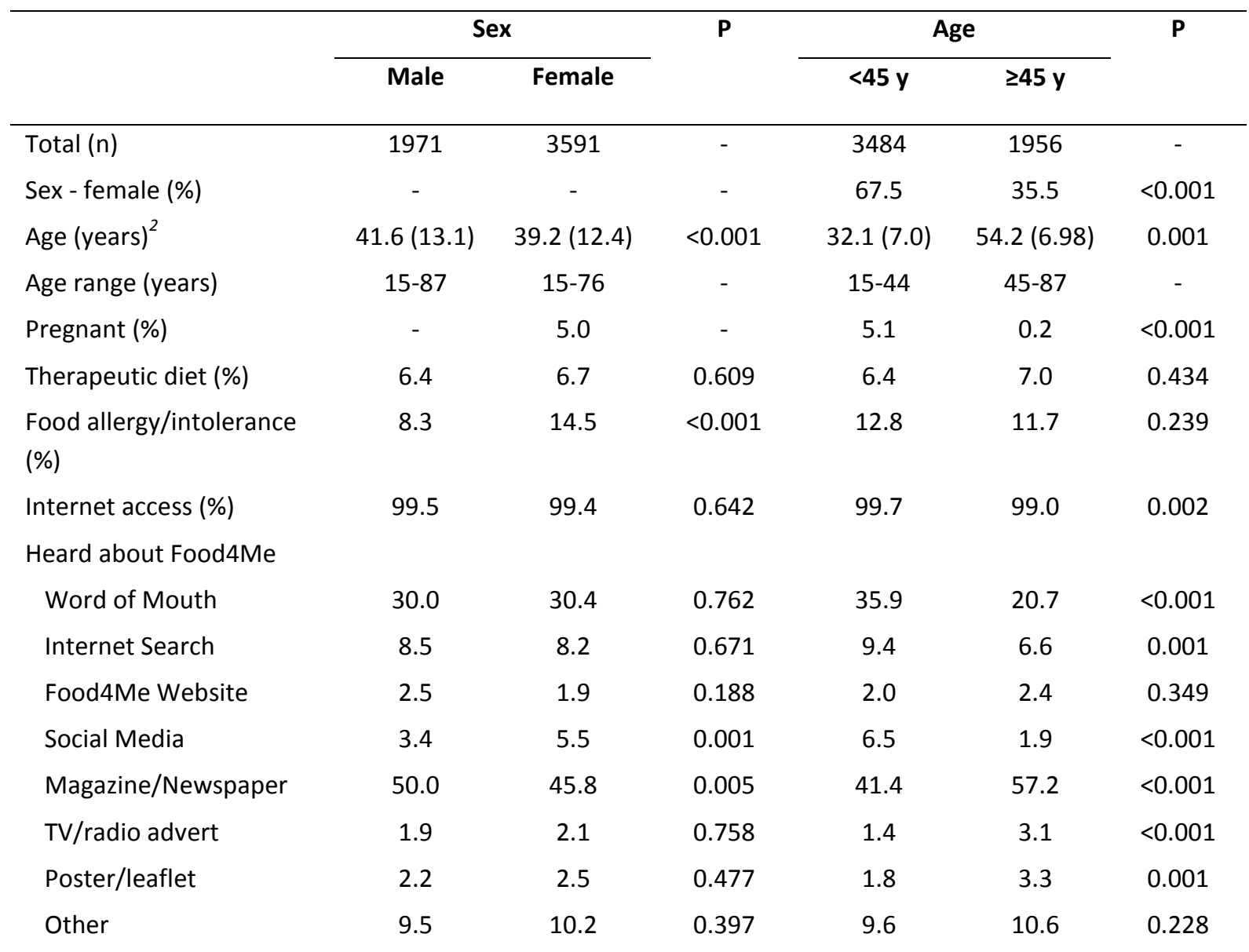

${ }^{1}$ Chi squared tests and ANOVA were used to test for significant differences across categorical and continuous variables respectively.

${ }^{2}$ Values are means \pm SDs 
Table 2 Characteristics of individuals by country; data obtained from the first screening questionnaire ${ }^{1}$

\begin{tabular}{|c|c|c|c|c|c|c|c|c|}
\hline & \multirow[t]{2}{*}{ All } & \multicolumn{7}{|c|}{ Country } \\
\hline & & UK & IRE & GER & NED & ESP & POL & GRE \\
\hline Total (n) & 5562 & 599 & 586 & 788 & 721 & 1839 & 458 & 571 \\
\hline Sex - female (\%) & 64.6 & $70.6 * *$ & 65.0 & $70.6 * *$ & $48.7^{* * *}$ & $61.9 *$ & $77.3^{* * *}$ & 68.0 \\
\hline Age (years) ${ }^{2}$ & $\begin{array}{c}40.0 \\
(12.7)\end{array}$ & $\begin{array}{c}37.2 \\
(9.6)^{*}\end{array}$ & $\begin{array}{c}38.0 \\
(12.4)^{*}\end{array}$ & $\begin{array}{c}44.5 \\
(13.9)^{*}\end{array}$ & $\begin{array}{c}49.3 \\
(13.9)^{*}\end{array}$ & $\begin{array}{c}38.4 \\
(9.6)^{*}\end{array}$ & $\begin{array}{c}36.0 \\
(12.6)^{*}\end{array}$ & $\begin{array}{c}37.7 \\
(11.5)^{*}\end{array}$ \\
\hline Age range (years) & $15-87$ & $17-87$ & $15-72$ & $15-80$ & $18-79$ & $18-78$ & $17-73$ & $18-70$ \\
\hline \multicolumn{9}{|l|}{ Age categories } \\
\hline$<45$ years $(\%)$ & 64.0 & $70.3 * *$ & $68.3^{*}$ & $44.5^{* * *}$ & $45.0 * * *$ & $76.1 * * *$ & $71.0^{* *}$ & $70.6^{* *}$ \\
\hline$\geq 45$ years $(\%)$ & 36.0 & $29.7 * *$ & $31.7^{*}$ & $55.5^{* * *}$ & $55.0 * * *$ & $23.9 * * *$ & $29.0 * *$ & $29.4^{* *}$ \\
\hline Pregnant (\%) & 3.3 & 2.7 & 2.9 & 2.3 & $0.3^{* * *}$ & $4.4^{*}$ & $4.2^{* * *}$ & 4.9 \\
\hline Therapeutic diet (\%) & 6.6 & $3.7^{* *}$ & 6.0 & $2.4^{* * *}$ & $4.3^{*}$ & $3.7^{* * *}$ & 5.7 & $9.6^{* *}$ \\
\hline Food allergy/ & 12.4 & $15.7^{*}$ & 12.5 & $17.1 * * *$ & 12.8 & $10.1^{* *}$ & 12.5 & $9.3^{*}$ \\
\hline \multicolumn{9}{|l|}{ Intolerance (\%) } \\
\hline Internet access (\%) & 99.5 & 100.0 & 99.7 & 99.5 & 99.8 & 99.7 & 99.6 & $97.2^{* * *}$ \\
\hline \multicolumn{9}{|c|}{ Heard about Food4Me (\%) } \\
\hline Word of Mouth & 30.3 & $41.8^{* * *}$ & $43.5^{* * *}$ & $15.9 * * *$ & $15.8^{* * *}$ & $17.3^{* * *}$ & $67.5^{* * *}$ & $59.7^{* * *}$ \\
\hline Internet Search & 8.3 & $15.4 * * *$ & 10.1 & $2.9 * * *$ & $1.7^{* * *}$ & $10.6 * *$ & $12.0^{* *}$ & $4.9 * *$ \\
\hline Food4Me Website & 2.1 & $4.1^{* *}$ & 1.3 & $1.0^{*}$ & $3.7^{*}$ & $1.0 * *$ & $4.4^{* *}$ & 2.6 \\
\hline Social Media & 4.8 & $8.8^{* * *}$ & $1.6^{*}$ & $1.7^{* * *}$ & $1.5^{* * *}$ & 5.2 & 3.1 & $10.5^{* * *}$ \\
\hline Magazine/ & 47.3 & $7.3^{* * *}$ & $3.6 * * *$ & $73.5^{* * *}$ & $76.8^{* * *}$ & $68.8 * * *$ & $5.7^{* * *}$ & $4.6 * * *$ \\
\hline \multicolumn{9}{|l|}{ Newspaper } \\
\hline TV/radio advert & 2.0 & $0.6^{*}$ & $24.8 * * *$ & $0.4^{* *}$ & 1.3 & $0.7^{* * *}$ & $0.2^{*}$ & 0.0 \\
\hline Poster/leaflet & 2.4 & $5.4 * * *$ & $8.5^{* * *}$ & $0.5^{* *}$ & 2.2 & 0.0 & $4.8 * *$ & $4.7^{* *}$ \\
\hline Other & 9.9 & $26.6 * * *$ & 12.1 & 11.2 & $5.5^{* * *}$ & $3.9 * * *$ & 9.2 & $16.5^{* * *}$ \\
\hline
\end{tabular}

${ }^{1}$ Multinomial regression analyses were used to test for significant differences across categorical variables. For multinomial comparisons across countries, the overall average was used as the reference group. ANOVA and Fisher-Hayter pairwise comparisons were used for continuous variables. Results were deemed significant at $* \mathrm{P}<0.05, * * \mathrm{P}<0.01$ and $* * * \mathrm{P}<0.001$.

${ }^{2}$ Values are means \pm SDs 
Table 3 Characteristics of individuals by sex and age group; data obtained from the second screening questionnaire ${ }^{1}$

\begin{tabular}{|c|c|c|c|c|c|c|}
\hline & \multicolumn{2}{|c|}{ Sex } & \multirow[t]{2}{*}{$\mathbf{P}$} & \multicolumn{2}{|c|}{ Age } & \multirow[t]{2}{*}{$\mathbf{P}$} \\
\hline & Male & Female & & $<45$ & $\geq 45$ & \\
\hline Total (n) & 1432 & 2379 & - & 2395 & 1416 & - \\
\hline Sex - female (\%) & - & - & - & 63.6 & 60.4 & 0.005 \\
\hline Age (years) ${ }^{2}$ & $41.6(13.1)$ & $39.4(12.7)$ & $<0.001$ & $31.9(7.06)$ & $54.2(7.04)$ & $<0.001$ \\
\hline Age range (years) & $18-80$ & $17-76$ & - & $17-44$ & $45-80$ & - \\
\hline \multicolumn{7}{|l|}{ Ethnicity (\%) } \\
\hline Caucasian & 96.6 & 97.1 & 0.410 & 96.3 & 97.8 & 0.011 \\
\hline Asians-Chinese & 0.5 & 0.7 & 0.478 & 0.8 & 0.2 & 0.016 \\
\hline Black & 0.1 & 0.2 & 0.622 & 0.1 & 0.3 & 0.273 \\
\hline Mixed & 1.5 & 1.4 & 0.841 & 1.5 & 1.3 & 0.558 \\
\hline Other & 1.3 & 0.7 & 0.040 & 1.2 & 0.4 & 0.014 \\
\hline \multicolumn{7}{|l|}{ Anthropometrics } \\
\hline Height $(m)^{2}$ & $1.8(0.1)$ & $1.7(0.1)$ & $<0.001$ & $1.7(0.1)$ & $1.7(0.1)$ & 0.7592 \\
\hline Weight $(\mathrm{kg})^{2}$ & $85.2(15.0)$ & $68.5(14.2)$ & $<0.001$ & $73.0(16.6)$ & $77.7(16.1)$ & $<0.001$ \\
\hline $\mathrm{BMI}\left(\mathrm{kgm}^{2}\right)^{2}$ & $25.0(4.9)$ & $26.5(4.9)$ & $<0.001$ & $26.7(4.5)$ & $24.9(5.1)$ & $<0.001$ \\
\hline \multicolumn{7}{|l|}{ BMI Classification (\%) } \\
\hline Under weight & 0.5 & 3.2 & $<0.001$ & 2.5 & 1.6 & 0.071 \\
\hline Normal Weight & 40.5 & 57.2 & $<0.001$ & 56.8 & 41.0 & $<0.001$ \\
\hline Overweight & 41.2 & 25.3 & $<0.001$ & 27.6 & 37.3 & $<0.001$ \\
\hline Obese & 17.8 & 14.4 & 0.006 & 13.1 & 20.1 & $<0.001$ \\
\hline \multicolumn{7}{|l|}{ Physical Activity $(\%)^{3}$} \\
\hline \multicolumn{7}{|l|}{ Occupational } \\
\hline Light & 73.9 & 72.3 & 0.382 & 69.3 & 78.9 & $<0.001$ \\
\hline Moderate & 22.1 & 26.7 & 0.007 & 28.8 & 18.7 & $<0.001$ \\
\hline Heavy & 4.0 & 0.1 & $<0.001$ & 1.9 & 2.4 & 0.375 \\
\hline \multicolumn{7}{|l|}{ Non-Occupational } \\
\hline Sedentary & 28.2 & 38.9 & $<0.001$ & 35.8 & 33.6 & 0.235 \\
\hline Moderately active & 54.5 & 51.9 & 0.182 & 50.9 & 56.1 & 0.008 \\
\hline Active & 17.3 & 9.2 & $<0.001$ & 13.3 & 10.3 & 0.020 \\
\hline \multicolumn{7}{|l|}{ Reason for interest (\%) } \\
\hline Personalised nutrition & 76.4 & 73.6 & 0.051 & 76.9 & 72.7 & 0.004 \\
\hline $\begin{array}{l}\text { Knowing what foods are } \\
\text { best }\end{array}$ & 82.9 & 79.3 & 0.026 & 81.8 & 78.8 & 0.007 \\
\hline Losing weight & 42.6 & 52.5 & $<0.001$ & 46.4 & 52.9 & $<0.001$ \\
\hline Gaining weight & 3.3 & 1.1 & $<0.001$ & 2.5 & 0.9 & $<0.001$ \\
\hline Concerns for health & 88.0 & 87.2 & 0.465 & 88.9 & 85.1 & 0.001 \\
\hline
\end{tabular}

\footnotetext{
${ }^{1}$ Chi squared tests and ANOVA were used to test for significant differences across categorical and continuous variables respectively.

${ }^{2}$ Values are means \pm SDs

${ }^{3}$ Physical activity was estimated from the food frequency questionnaire in 2763 individuals
} 
${ }^{6}$ Compared with less than 1 hour 
Table 4 Characteristics of individuals by country; data obtained from the second screening questionnaire ${ }^{1}$

\begin{tabular}{|c|c|c|c|c|c|c|c|c|}
\hline & \multirow[t]{2}{*}{ All } & \multicolumn{7}{|c|}{ Country } \\
\hline & & UK & IRE & GER & NED & ESP & POL & GRE \\
\hline Total (n) & 3811 & 413 & 405 & 535 & 511 & 1206 & 340 & 401 \\
\hline Sex - female (\%) & 62.4 & 66.8 & 62.7 & 66.4 & $56.6^{*}$ & $57.2^{* *}$ & $73.8^{* * *}$ & 65.8 \\
\hline Age (years) & $40.2(12.9)$ & $\begin{array}{c}37.0 \\
(13.3)\end{array}$ & $\begin{array}{c}37.9 \\
(12.4)\end{array}$ & $\begin{array}{c}44.9 \\
(13.9)\end{array}$ & $\begin{array}{c}49.2 \\
(14.2)\end{array}$ & $\begin{array}{c}38.3 \\
(9.47)\end{array}$ & $\begin{array}{c}36.3 \\
(12.8)\end{array}$ & $\begin{array}{c}37.4 \\
(11.6)\end{array}$ \\
\hline Age range (years) ${ }^{2}$ & $17-80$ & $18-72$ & $18-72$ & $17-80$ & $18-79$ & $18-70$ & $17-73$ & $18-70$ \\
\hline \multicolumn{9}{|l|}{ Age categories (\%) } \\
\hline$<45$ years & 62.8 & $70.5^{* *}$ & 67.7 & $44.5 * * *$ & $31.5^{* * *}$ & $76.0 * * *$ & $69.7^{*}$ & $69.3^{*}$ \\
\hline$\geq 45$ years & 37.2 & $29.5^{* *}$ & 32.3 & $55.5^{* * *}$ & $68.5^{* * *}$ & $24.0^{* * *}$ & $30.3^{*}$ & $30.7^{*}$ \\
\hline \multicolumn{9}{|l|}{ Ethnicity (\%) } \\
\hline Caucasian & 96.9 & $89.6 * * *$ & 97.5 & 96.8 & 96.5 & 97.8 & 100 & $99.0^{*}$ \\
\hline Asians-Chinese & 0.6 & $3.2 * * *$ & 1.0 & 0.2 & 0.8 & 0.1 & 0.0 & 0.0 \\
\hline Blacks & 0.2 & 0.5 & 0.0 & 0.4 & 0.2 & 0.1 & 0.0 & 0.3 \\
\hline Mixed & 1.4 & $3.2^{* *}$ & 1.2 & 1.7 & 1.4 & 1.7 & 0.0 & 0.0 \\
\hline Other & 0.9 & $3.6 * * *$ & 0.3 & 0.9 & 1.2 & 0.4 & 0.0 & 0.8 \\
\hline \multicolumn{9}{|l|}{ Anthropometrics } \\
\hline Height $(m)^{2}$ & $1.7(0.1)$ & $1.7(0.1)$ & $1.7(0.1)$ & $1.7(0.1)^{*}$ & $1.7(0.1)^{*}$ & $1.7(0.1)^{*}$ & $1.7(0.1)^{*}$ & $1.7(0.1)^{*}$ \\
\hline Weight $(\mathrm{kg})^{2}$ & $74.8(16.6)$ & $\begin{array}{c}73.4 \\
(15.6)\end{array}$ & $\begin{array}{c}75.2 \\
(16.9)\end{array}$ & $\begin{array}{c}73.2 \\
(14.2)\end{array}$ & $\begin{array}{c}77.3 \\
(15.0)^{*}\end{array}$ & $\begin{array}{c}74.8 \\
(17.9)\end{array}$ & $\begin{array}{c}72.1 \\
(16.3)\end{array}$ & $\begin{array}{c}76.4 \\
(17.8)\end{array}$ \\
\hline $\mathrm{BMI}\left(\mathrm{kgm}^{2}\right)^{2}$ & $25.6(5.0)$ & $25.5(5.0)$ & 25.7 (4.9) & $\begin{array}{c}24.4 \\
(3.9)^{*}\end{array}$ & $25.4(4.6)$ & $25.9(5.2)$ & $25.1(4.9)$ & $\begin{array}{c}26.7 \\
(5.8)^{*}\end{array}$ \\
\hline \multicolumn{9}{|l|}{ BMI Classification (\%) } \\
\hline Underweight & 2.2 & 2.0 & 2.3 & 2.6 & 2.0 & 1.9 & 3.6 & 1.5 \\
\hline Normal Weight & 50.9 & 53.0 & 49.1 & $59.1 * * *$ & 52.6 & 49.0 & 51.2 & $42.7^{* *}$ \\
\hline Overweight & 31.2 & 31.0 & 31.2 & 28.1 & 32.1 & 31.6 & 29.3 & 35.2 \\
\hline Obese & 15.7 & 14.0 & 17.4 & $10.2^{* *}$ & 13.4 & 17.5 & 16.0 & $20.6^{*}$ \\
\hline \multicolumn{9}{|l|}{ Physical Activity $(\%)^{3}$} \\
\hline \multicolumn{9}{|l|}{ Occupational } \\
\hline Light & 72.9 & 69.5 & 69.6 & $79.0^{*}$ & $62.5^{* * *}$ & $82.2^{* * *}$ & $66.8^{*}$ & 70.6 \\
\hline Moderate & 25.0 & 27.5 & 28.1 & 20.4 & $34.1 * * *$ & $16.8^{* * *}$ & $31.2^{*}$ & 26.0 \\
\hline Heavy & 2.1 & 3.0 & 2.3 & 0.5 & 3.4 & 1.1 & 2.1 & 3.4 \\
\hline \multicolumn{9}{|l|}{ Non-Occupational } \\
\hline Sedentary & 35.0 & $25.5^{* *}$ & $21.7^{* * *}$ & 31.5 & $23.4 * * *$ & $40.7^{* *}$ & $48.6 * * *$ & $50.2 * * *$ \\
\hline Moderately active & 52.9 & 55.0 & $67.6^{* * *}$ & $61.3^{* *}$ & $64.8^{* * *}$ & $46.6^{* *}$ & $42.1^{* *}$ & $35.3^{* * *}$ \\
\hline Active & 12.2 & $19.5^{* * *}$ & 10.7 & $7.3^{* *}$ & 11.8 & 12.7 & 9.3 & 14.6 \\
\hline \multicolumn{9}{|c|}{ Reason for interest (\%) } \\
\hline $\begin{array}{l}\text { Personalised } \\
\text { nutrition }\end{array}$ & 75.4 & $83.3^{* * *}$ & $82.0^{* *}$ & 77.2 & 78.7 & $78.7^{*}$ & $55.6 * * *$ & $60.6 * * *$ \\
\hline Knowing what & 80.7 & $73.1 * * *$ & 76.8 & $74.6 * *$ & $81.0 * *$ & $87.7^{* * *}$ & $86.8^{* *}$ & $73.6 * *$ \\
\hline
\end{tabular}


foods are best

Losing weight

Gaining weight

44.6

47.7

45.2

$36.6 * * *$

51.2

53.2

$63.3^{* * *}$

Concerns for

1.9

1.0

2.1

1.2

2.3

2.4

health

${ }^{1}$ Multinomial regression analyses were used to test for significant differences across categorical variables. For multinomial comparisons across countries, the overall average was used as the reference group. ANOVA and Fisher-Hayter pairwise comparisons were used for continuous variables. Results were deemed significant at $* \mathrm{P}<0.05, * * \mathrm{P}<0.01$ and $* * * \mathrm{P}<0.001$.

${ }^{2}$ Values are means \pm SDs

${ }^{3}$ Physical activity was estimated from the food frequency questionnaire in 2763 individuals 


\section{Excluded, $\mathrm{n}=1631^{*}$}

- Not willing to share information,

$\mathrm{n}=36$

- Incomplete $2^{\text {nd }}$ screening

questionnaire, $\mathrm{n}=526$

- Pregnant, $n=181$

- Therapeutic diet, $n=352$

- Food allergy/intolerance, $n=658$

- No internet, $n=28$

\section{Excluded, $\mathrm{n}=1157$}

- Study design and sample size

estimation required $\mathrm{n}=1607$ only
Participants who registered online

for the Food4Me Study

$n=5562$

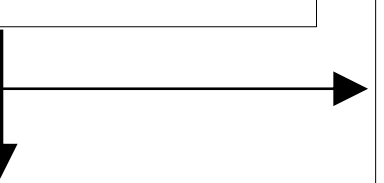

Excluded, $\mathrm{n}=120$

- Incomplete $1^{\text {st }}$ screening

questionnaire $1^{\text {st }}$ Screening questionnaire $n=5442$

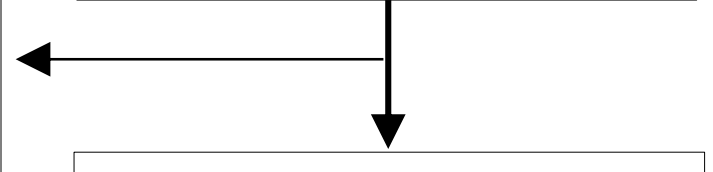

$2^{\text {nd }}$ Screening questionnaire $n=3811$

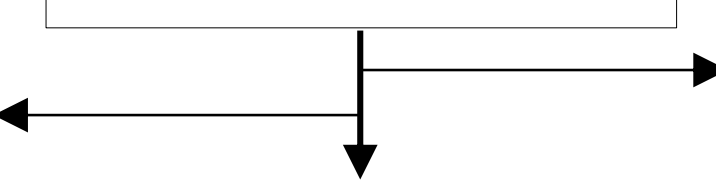

Participants randomised into one of the 4 arms on the intervention $\mathrm{n}=1607$

\section{Excluded, $n=1047$ *}

- Second consent not given, $n=238$

- Incomplete/under-reported food frequency questionnaire, $n=598$

- Food allergy/intolerance, $n=93$

- Therapeutic diet, $n=199$

- Limited physical activity $n=252$

* Total number of participants reporting one or more exclusion criteria

Fig 1. Food4Me Proof of Principle Study flow-chart 


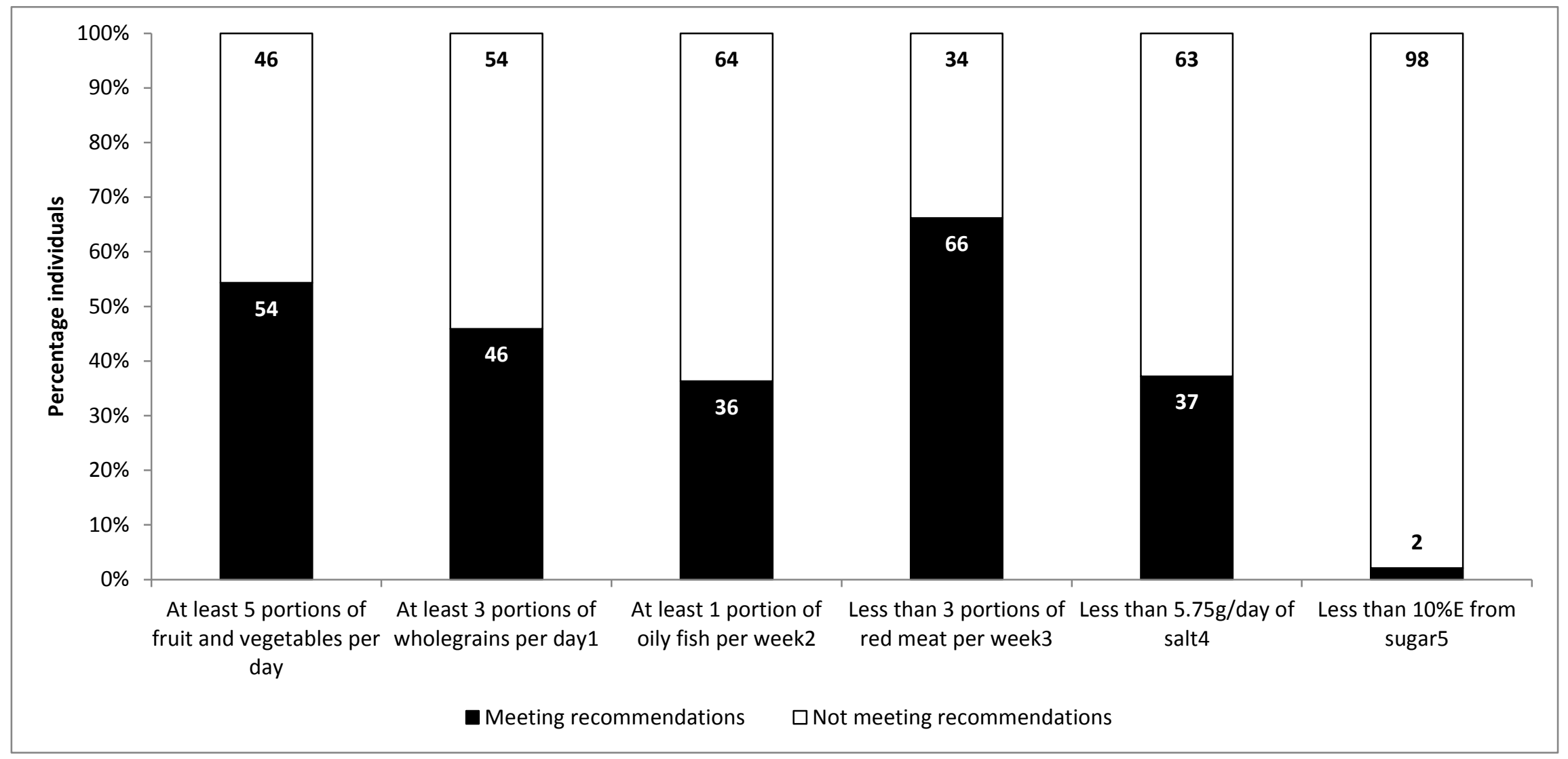

Fig 2. Percentage of participants meeting food-based dietary recommendations.

${ }^{1}$ Equivalent to $48 \mathrm{~g} / \mathrm{day} ;{ }^{2}$ More than $150 \mathrm{~g} /$ week of oily fish; ${ }^{3}$ Consume less than $450 \mathrm{~g} /$ week of red or processed meat; ${ }^{4}$ Based on loM recommendations[33]; ${ }^{5}$ Based on draft Scientific Advisory Committee for Nutrition (SACN) recommendations [27] 


\section{Online Resource 1 (Supplementary material)}
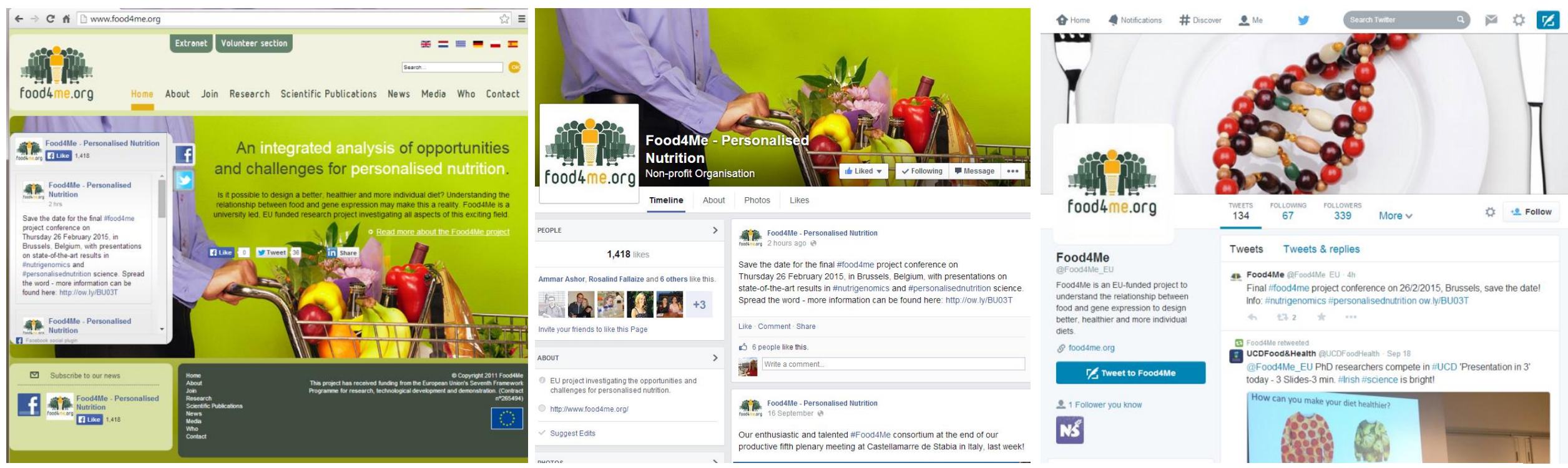


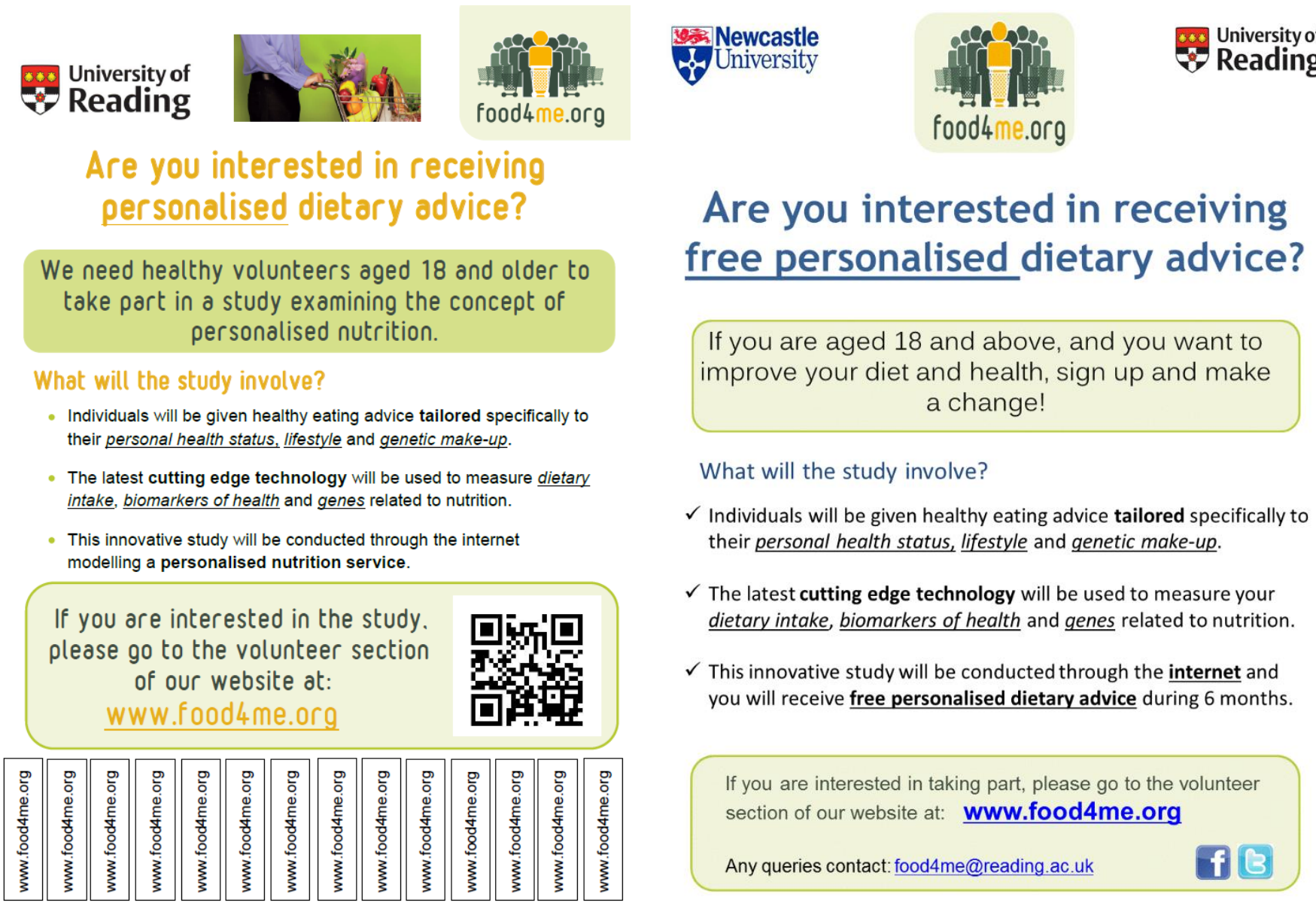

Figure S2. Examples of UK poster advertisements used during recruitment 
Methods: Screening Questionnaires

Unlike in other countries, Dutch individuals had the opportunity to register and then choose whether or not to complete the first screening questionnaire. IP addresses and cookies were not used to identify individuals, as unique usernames prevented participants from entering duplicate entries from the same user and allowed individuals using the same computer, e.g. family members, to register for the study. No monetary incentives were offered for completing the screening questionnaires. Participants were informed that, if they were randomised into the intervention study, they would receive healthy eating and lifestyle advice, as well as non-diagnostic information relating to their health status during, or on completion of, the study. No randomization of adaptive questioning was employed. Automated completeness checks prevented participants from submitting incomplete questionnaire responses. Completion rates were estimated as the ratio of users who finished the survey to users who provided their consent to participate. Once questionnaires were submitted, participants could not change their responses and these responses were later extracted from the server into databases for statistical analysis. Under-reporting of dietary intakes via the FFQ was identified from a comparison between expected energy expenditure, based on a multiple (1.1) of predicted basal metabolic rate and reported energy intakes [34]. Participants who under-reported in their FFQ were asked to repeat the FFQ up to two times before being excluded. Participants had 7 days to complete the screening questionnaires. A reminder was sent at day 5; if they did not complete the screening FFQ by day 7, they were excluded from the study. Individuals who were deemed unsuitable for the study received an email notification that they did not match the inclusion criteria and so were excluded from further elements of the study. 
Table S1 Health-related characteristics by sex and age group; data obtained from the second screening questionnaire $^{1}$

\begin{tabular}{|c|c|c|c|c|c|c|}
\hline & \multicolumn{2}{|c|}{ Sex } & \multirow[t]{2}{*}{$\mathbf{P}$} & \multicolumn{2}{|c|}{ Age } & \multirow[t]{2}{*}{$\mathbf{P}$} \\
\hline & Male & Female & & $<45$ & $\geq 45$ & \\
\hline Total $(n)$ & 1432 & 2379 & - & 2395 & 1416 & - \\
\hline \multicolumn{7}{|l|}{ Medication use } \\
\hline Prescribed & 25.0 & 38.0 & $<0.001$ & 26.3 & 44.8 & $<0.001$ \\
\hline Non-prescribed & 8.7 & 13.1 & $<0.001$ & 9.6 & 14.5 & $<0.001$ \\
\hline \multicolumn{7}{|l|}{ Diseases } \\
\hline Cancer & 1.8 & 2.6 & 0.085 & 1.1 & 4.3 & $<0.001$ \\
\hline High blood pressure & 12.6 & 7.3 & $<0.001$ & 3.6 & 18.9 & $<0.001$ \\
\hline Heart disease & 3.4 & 0.9 & $<0.001$ & 0.7 & 3.8 & $<0.001$ \\
\hline Liver disease & 2.4 & 1.2 & 0.007 & 1.4 & 2.1 & 0.083 \\
\hline Kidney disease & 1.1 & 0.9 & 0.708 & 0.7 & 1.4 & 0.033 \\
\hline Arthritis & 2.1 & 3.2 & 0.046 & 0.8 & 6.1 & $<0.001$ \\
\hline Osteoporosis & 0.6 & 1.6 & 0.004 & 0.3 & 2.8 & $<0.001$ \\
\hline Ulcers & 2.3 & 1.6 & 0.114 & 1.2 & 3.0 & $<0.001$ \\
\hline Fibromyalgia & 0.1 & 1.1 & 0.001 & 0.3 & 1.5 & $<0.001$ \\
\hline Diabetes & 1.2 & 0.8 & 0.230 & 0.4 & 1.8 & $<0.001$ \\
\hline Lung disease & 3.0 & 2.7 & 0.519 & 2.7 & 2.9 & 0.742 \\
\hline Allergies & 20.9 & 19.3 & 0.235 & 20.7 & 18.6 & 0.118 \\
\hline Epilepsy & 0.5 & 0.4 & 0.759 & 0.6 & 0.2 & 0.095 \\
\hline Thyroid disease & 1.5 & 11.3 & $<0.001$ & 5.4 & 11.3 & $<0.001$ \\
\hline Diagnosed anaemia & 1.5 & 9.8 & $<0.001$ & 6.4 & 7.2 & 0.357 \\
\hline Blood disorders & 0.8 & 2.0 & 0.005 & 1.8 & 1.3 & 0.248 \\
\hline Alcoholism & 0.4 & 0.0 & 0.008 & 0.1 & 0.3 & 0.060 \\
\hline Drug addiction & 0.4 & 0.1 & 0.071 & 0.2 & 0.3 & 0.651 \\
\hline Depression & 5.2 & 8.4 & $<0.001$ & 6.0 & 9.3 & $<0.001$ \\
\hline Smoker & 13.5 & 12.6 & 0.417 & 15.0 & 9.46 & $<0.001$ \\
\hline Ex-smoker & 37.0 & 33.9 & 0.083 & 26.1 & 49.5 & $<0.001$ \\
\hline
\end{tabular}

${ }^{1}$ Chi squared tests and ANOVA were used to test for significant differences across categorical and continuous variables respectively.

${ }^{2}$ Values are means \pm SDs 
Table S2 Health-related characteristics of individuals by country; data obtained from the second screening questionnaire $^{1}$

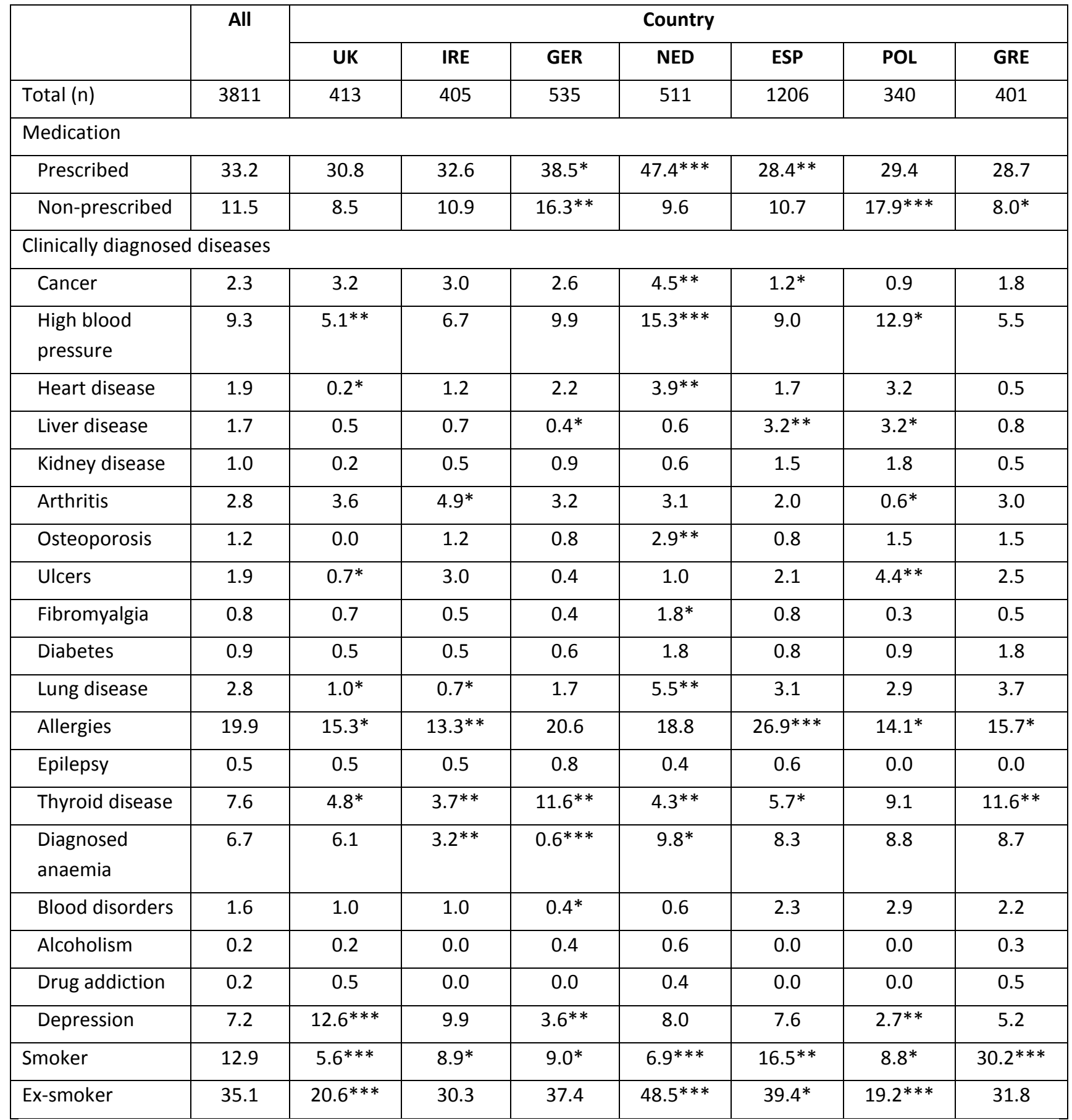

${ }^{1}$ Multinomial regression analyses were used to test for significant differences across categorical variables. For multinomial comparisons across countries, the overall average was used as the reference group. ANOVA and FisherHayter pairwise comparisons were used for continuous variables. Results were deemed significant at * $\mathrm{P}<0.05, * *$ $\mathrm{P}<0.01$ and $* * * \mathrm{P}<0.001$.

${ }^{2}$ Values are means \pm SDs 
Table S3. Mean intakes of key foods and food groups ${ }^{1}$

\begin{tabular}{|c|c|c|c|c|c|c|}
\hline Dietary target & Fruit and vegetables & Wholegrain products & Oily fish & Red meat & Salt & Sugars \\
\hline & g/day (SD) & g/day (SD) & g/week (SD) & g/week (SD) & g/day (SD) & \% energy (SD) \\
\hline All & $651.4(488.6)$ & $173.0(208.5)$ & $171.0(236.3)$ & $573.0(516.9)$ & $7.56(4.9)$ & $21.4(6.6)$ \\
\hline \multicolumn{7}{|l|}{ Sex } \\
\hline Male & $645.2(410.8)$ & $188.6(237.7)$ & $200.0(237.2)$ & $713.0(597.3)$ & 8.56 (4.79) & $20.4(6.3)$ \\
\hline Female & $655.0(528.7)$ & $163.9(188.8)$ & $154.2(234.2)$ & $491.4(443.8)$ & $6.97(4.83)$ & $21.4(6.6)$ \\
\hline$P$ & 0.611 & 0.003 & $<0.001$ & $<0.001$ & $<0.001$ & $<0.001$ \\
\hline \multicolumn{7}{|l|}{ Age category } \\
\hline$<45$ years & $633.4(519.6)$ & $156.7(198.9)$ & $169.8(222.8)$ & $594.5(548.4)$ & $7.64(4.50)$ & $21.5(6.5)$ \\
\hline$\geq 45$ years & $681.3(430.5)$ & $200.2(220.9)$ & $173.1(257.5)$ & $537.2(457.5)$ & $7.43(5.45)$ & $21.2(6.6)$ \\
\hline$P$ & 0.013 & $<0.001$ & 0.719 & 0.005 & 0.272 & 0.238 \\
\hline \multicolumn{7}{|l|}{ Country } \\
\hline UK & $687.0(425.3)$ & $176.2(192.5)$ & $168.2(191.6)$ & $466.7(392.2)^{*}$ & $7.3(4.1)$ & $22.9(6.4)^{*}$ \\
\hline Ireland & $696.7(881.9)$ & $222.7(152.8)^{*}$ & $163.0(224.7)$ & $592.4(492.0)$ & $7.7(3.70)$ & $21.3(6.3)$ \\
\hline Germany & $675.8(398.4)$ & $182.2(161.6)$ & $104.9(142.6)^{*}$ & $445.1(599.3)^{*}$ & $6.9(4.1)$ & $21.6(6.3)$ \\
\hline The Netherlands & $647.5(351.3)$ & $319.2(290.2)^{*}$ & $152.0(213.8)$ & $482.3(445.8)^{*}$ & $8.3(4.4)^{*}$ & $20.6(6.1)$ \\
\hline Spain & $641.8(419.9)$ & 73.6 (110.6)* & $260.3(249.8)^{*}$ & $746.1(537.3)^{*}$ & $7.9(6.3)$ & $21.3(6.9)$ \\
\hline Poland & $595.8(436.8)$ & 214.9 (268.7)* & $132.8(176.9)$ & $536.1(538.7)$ & $8.2(4.8)$ & $21.8(7.0)$ \\
\hline
\end{tabular}

${ }^{1}$ Multinomial regression analyses were used to test for significant differences across categorical variables. For multinomial comparisons across countries, the overall average was used as the reference group. ANOVA and Fisher-Hayter pairwise comparisons were used for continuous variables. Results across countries were deemed significant at $* \mathrm{P}<0.05$ 

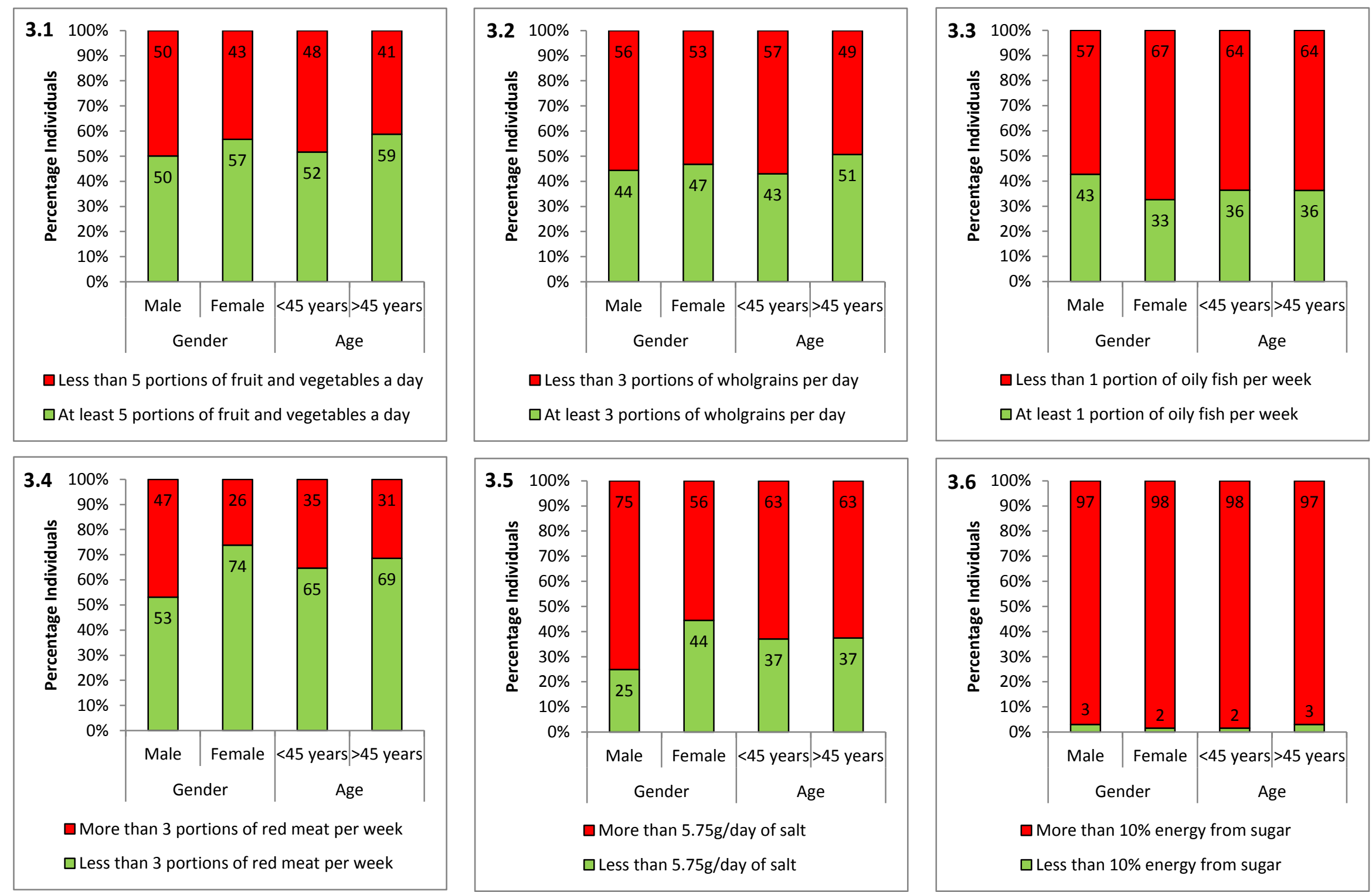

口More than 3 portions of red meat per week 口Less than 3 portions of red meat per week 
Figure S3. Percentage of individuals meeting the dietary recommendations for 3.1 At least 5 portions of fruit and vegetables a day (400g/day); 3.2 At least 3 portions of whole grain per day (48g/day); 3.3 At least 1 or more servings of oily fish per week (150g/week); 3.4 Less than 3 portions of red or processed meat per week (450g/week); 3.5 Less than $5.75 \mathrm{~g}$ salt per day; 3.6 Less than $10 \%$ energy from sugars by age and sex. 

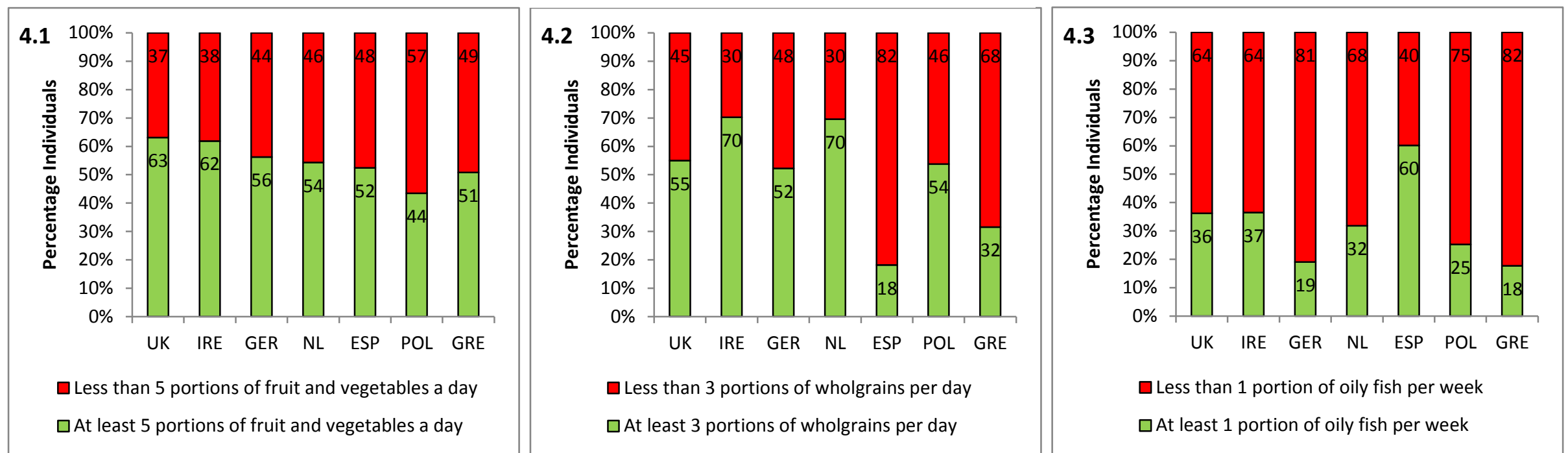

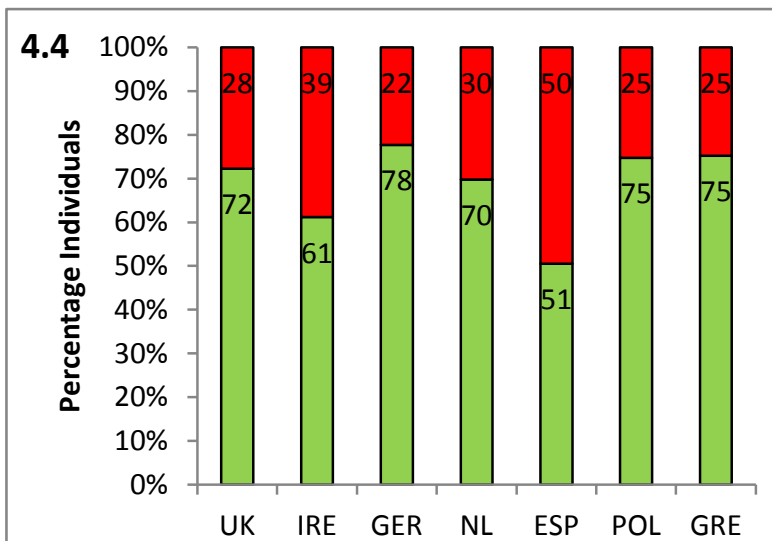

More than 3 portions of red meat per week

口Less than 3 portions of red meat per week
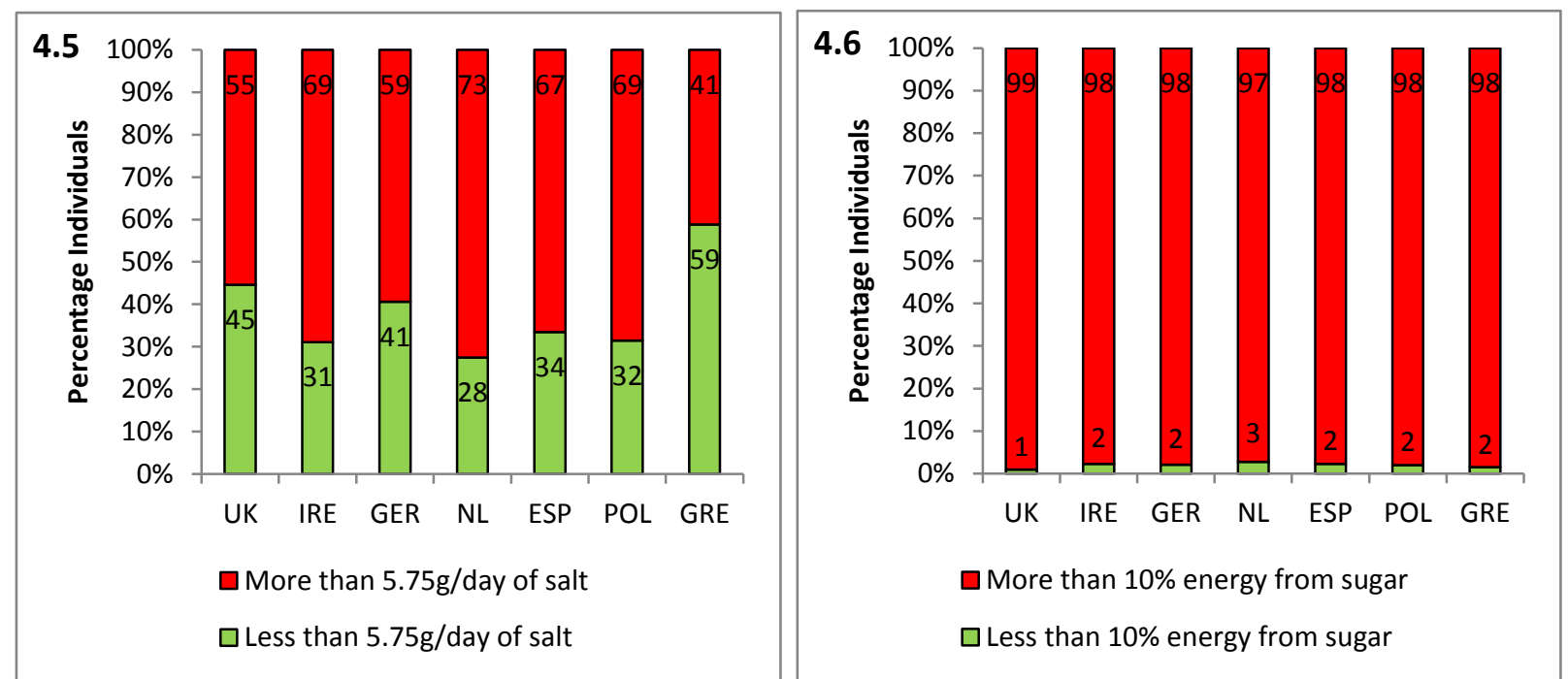

Figure S4. Percentage of individuals meeting the dietary recommendations for 4.1 At least 5 portions of fruit and vegetables a day (400g/day); 4.2 At least 3 portions of whole grain per day (48g/day); 4.3 At least 1 or more servings of oily fish per week (150g/week); 4.4 Less than 3 portions of red or processed meat per week (450g/week); 4.5 Less than $5.75 \mathrm{~g}$ salt per day; 4.6 Less than $10 \%$ energy from sugars by country 

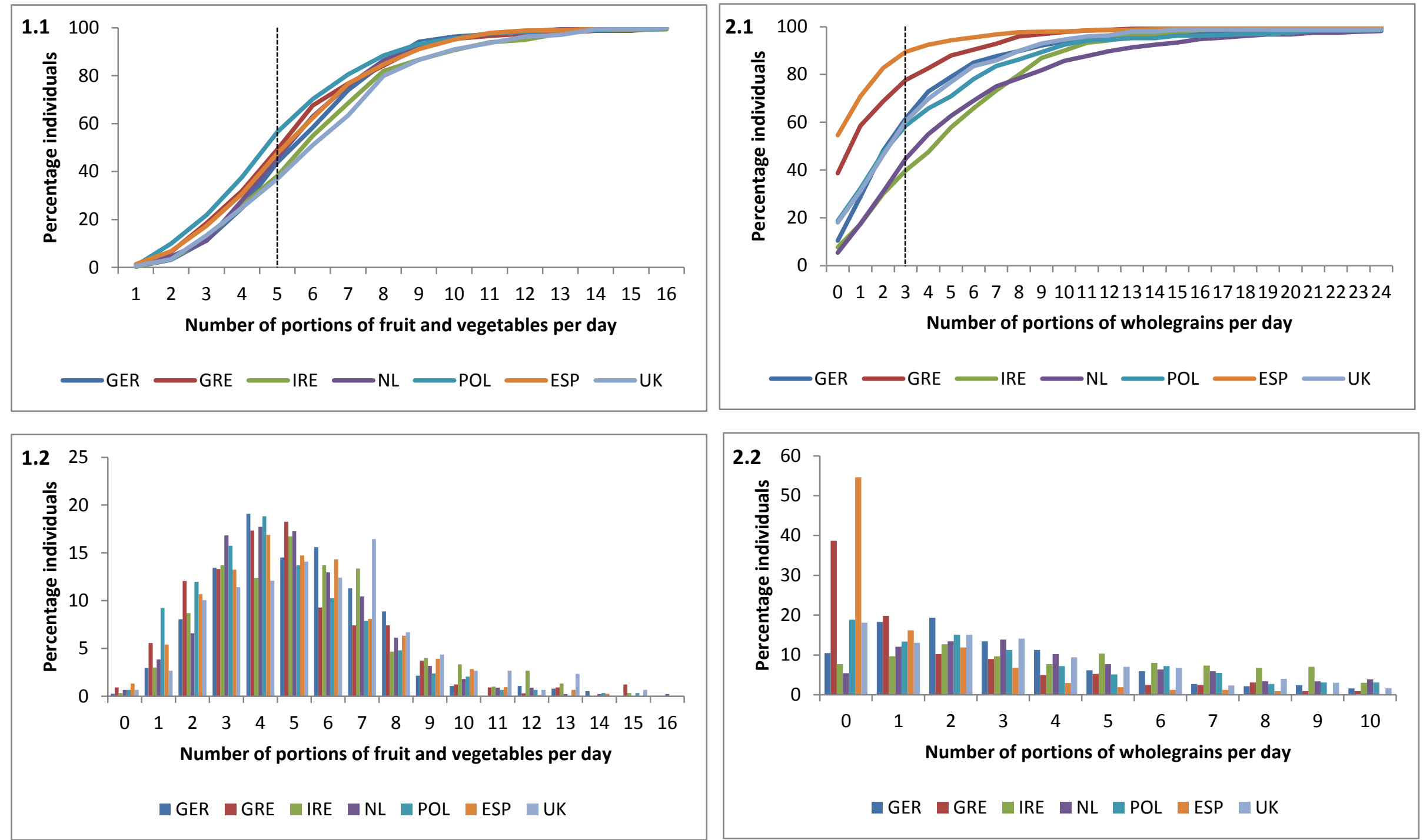

Figure S5. Cumulative (.1) and relative percentage (.2) of portion consumption of 1 fruit and vegetables and 2 wholegrain by country. The recommended number of portions is indicated by the dotted line. 

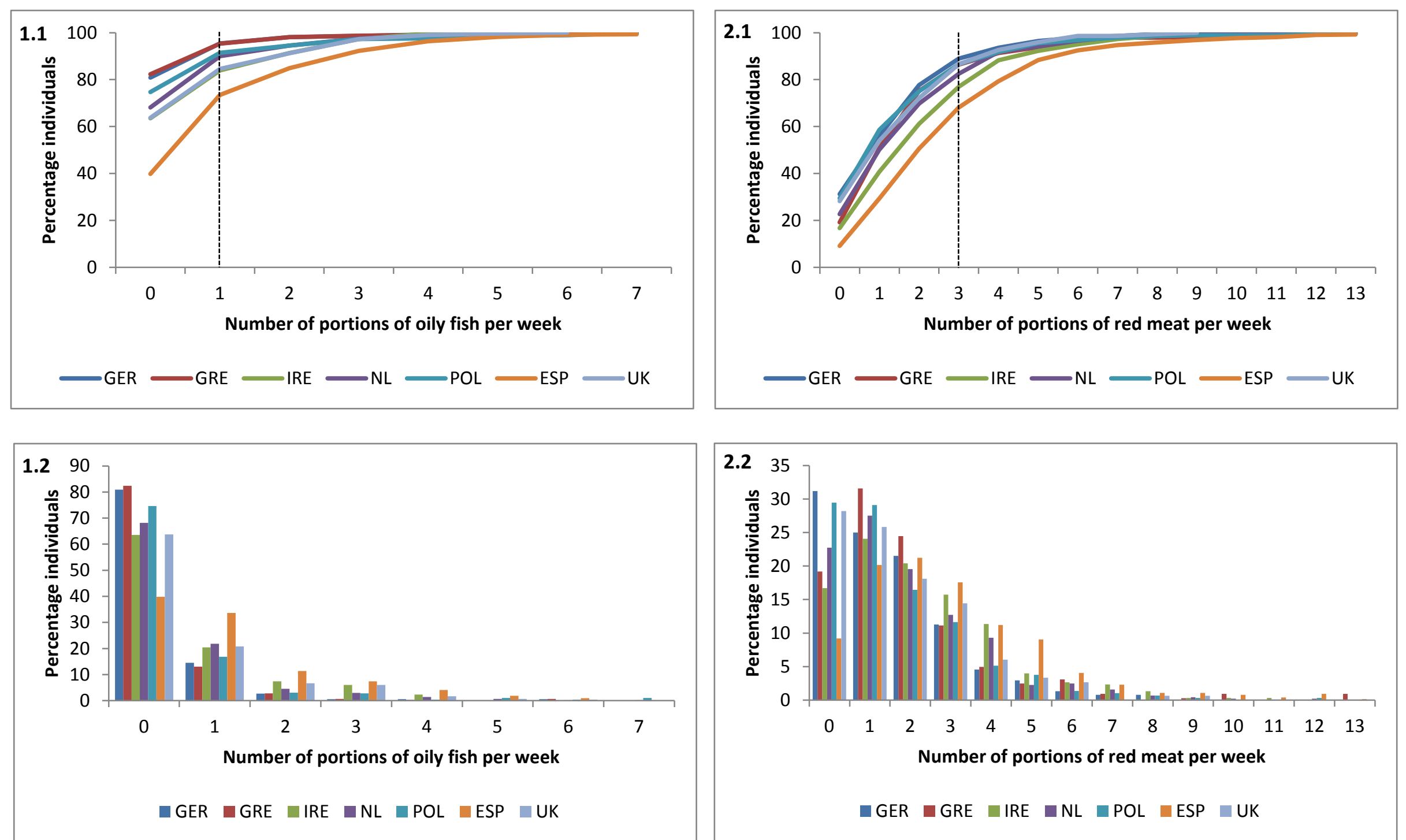

Figure S6. Cumulative (.1) and relative percentage (.2) of portion consumption of 1 fruit and vegetables and 2 wholegrain by country. The recommended number of portions is indicated by the dotted line. 